И. В. Савиткина. Нейропсихологический подход в диагностике и коррекции нарушений речи у дошкольников

Научная статья

УДК 376.37

DOI: 10.18101/2307-3330-2021-2-65-70

\title{
НЕЙРОПСИХОЛОГИЧЕСКИЙ ПОДХОД В ДИАГНОСТИКЕ И КОРРЕКЦИИ НАРУШЕНИЙ РЕЧИ У ДОШКОЛЬНИКОВ
}

\author{
(C) Савиткина Ирина Владимировна \\ старший преподаватель, \\ Бурятский государственный университет имени Доржи Банзарова \\ Россия, 670000, г. Улан-Удэ, ул. Смолина, 24a \\ savitirina@mail.ru
}

\begin{abstract}
Аннотация. Статья посвящена актуальности применения нейропсихологического подхода в современной логопедии и образовании детей в целом. Представленный материал дает понимание важности и исключительности использования данного метода при диагностике и коррекции не только различных речевых нарушений, но и отклонений в психофизическом развитии. Автором дан обобщенный психоневрологический портрет ребенка в контексте понимания проблем социализации современного ребенка, проблем его психического развития и включения всех субъектов воспитательно-образовательного процесса в работу по оказанию своевременной качественной помощи. В связи с этим материалы содержат описание опыта взаимодействия со всеми субъектами образовательного процесса в конкретном дошкольном учреждении в ходе коррекционно-развивающего воздействия, описаны развивающая предметная среда и используемые в работе методические материалы.

Ключевые слова: нейропсихология, нейрологопедия, речепорождение, коррекционное воздействие, нейростимуляция, сенсорная интеграция генерализации языковых явлений, восприятие речи, восприятие речевой активности, психоневрологический портрет.
\end{abstract}

\section{Для цитирования}

Савиткина И. В. Нейропсихологический подход в диагностике и коррекции нарушений речи у дошкольников // Вестник Бурятского государственного университета. Образование. Личность. Общество. 2021. № 2. С. 65-70. Всякое слово имеет первоначальный образ-представление, и
рост словаря прямо связан с образованием многочисленных и
многообразных связей между предметным образом и словом

Л. С. Выготский

Несмотря на многолетний опыт работы в области дошкольной логопедии, на сформировавшийся и определенным образом сложившийся свой почерк во взаимодействии с детьми, на достаточно высокий уровень знаний, работать не стало легче! И это связано с тем, что дошкольная популяция детей очень сильно меняется и далеко не в лучшую сторону, общая картина детского онтогенеза становиться сложной и довольно разнородной. На это существует множество разных объективных и субъективных причин. Многие современные педагоги осознают - работать традиционно, «по-старому» уже нельзя. Чтобы быть эффек- 
тивным и результативным невозможно стоять на месте. Для этого нужно многое менять и в методических подходах, и в работе с детьми, а также в диагностике, и коррекции различных нарушений психофизического развития ребенка.

Федеральный государственный стандарт дошкольного образования разработан с учетом всех этих моментов и вполне позволяет расти и развиваться. Один из методов результативных изменений в работе педагога является нейропсихологический подход в диагностике и коррекции различных отклонений, включая нарушение речи. Ключевыми словами данного определения являются «нейропсихологический подход», то есть подразумевающий знания нейропсихологии.

Нейропсихология - наука о мозговой организации психических функций. А. Р. Лурия о ценности нейропсихологических наук писал: «Задача нейропсихологии - это изучение мозговых основ психической деятельности человека с привлечением новых, психологических, методов для топической диагностики локальных поражений мозга» [10, с. 6].

В современном мире эта наука чрезвычайно востребована и имеет прикладную практику во многих областях образовательной деятельности. Существует нейропсихология детского возраста, которая изучает формирование мозговой организации психических функций в процессе индивидуального развития ребенка. Она помогает выявлять актуальное состояние высших психических функций, механизм их нарушений, выстраивать программы по преодолению нарушений. Разработаны модифицированные схемы адаптированного нейропсихологического исследования дошкольников и младших школьников и анализа результатов нейропсихологического исследования. Все это внедряется, чтобы установить определенные ориентиры в возможностях нейропсихологического подхода к диагностике речевых и неречевых нарушений у детей, не только для учителей-логопедов, но и для других специалистов.

Что подтверждено словами А. В. Семенович в работе «Нейропсихологическая коррекция в детском возрасте», где она раскрывает сущность «метода замещающего онтогенеза» и четко определяет значимость данного подхода. «Нейропсихологический анализ проблем отклоняющегося развития, активно развиваемый в нашей стране с начала 1980-х гг., сразу зарекомендовал себя как наиболее надежный и продуктивный. Это закономерно, поскольку в его основе лежит мощная методологическая и научно-практическая база, разработанная в общей нейропсихологии, нейропсихологии детского возраста, теории нейропсихологической реабилитации» $[13$, с. 12$]$.

Сферы применения нейропсихологии:

- в практике логопеда, дефектолога для понимания мозговых механизмов речевых нарушений у взрослых и детей;

- в работе психолога с детьми, имеющими трудности обучения;

- в клинической практике при работе с детьми и подростками, имеющими нарушения психического развития и поведения;

- для воспитателей, желающих понимать мозговые механизмы развития психики детей с раннего возраста.

Специалисты со знанием основ нейропсихологии, нейродефектологии сегодня - одни из самых востребованных. Сегодня невозможно представить рабо- 
И. В. Савиткина. Нейропсихологический подход в диагностике и коррекции нарушений речи у дошкольников

ту логопеда без применения именно нейропсихологического подхода. Так как речь - это высшая интегративная функция, нарушения которой чаще всего ведет к различным расстройствам личности. Благодаря исследованиям гениальных ученых (лингвистов, психолингвистов, психологов, нейропсихологов, дефектологов, педагогов) глобально раскрыта теория речевой деятельности, изучены сложнейшие механизмы речепорождения. Базовым положением данной теории является идея о развитии речи ребенка в результате генерализации языковых явлений, восприятия речи и собственной речевой активности. И все это организуется только за счет правильного и здорового созревания мозговых структур, своевременного формирования всей центральной системы дошкольника. Все это нашло отражение в научных исследованиях Л. С. Выготского, Н. И. Жинкина, А. Р. Лурии, А. А. Леонтьева, Т. В. Ахутиной, И. А. Зимней, Т. Г. Визель и др.

Конечно, эти знания даются в рамках преподавания таких дисциплин, как психолингвистика, нейропсихология, логопсихология и основы логопедии для студентов, обучающихся на дефектологических факультетах.

Также нужно сказать, что в логопедии речь рассматривается не только как средство общения. Речь представляется нам как система, состоящая из определенных структурных компонентов: фонетико-фонематический, лексикограмматический, семантико-синтаксический компоненты. Это определенная последовательность языковых единиц (фонем, морфем, слов, предложений), регулируемая законами языка и работой сознания, формирующего ту или иную мысль. И оказывая ребенку логопедическую помощь, логопед воздействует не только на речевую систему в целом, на все высшие психические функции ребенка, во многом заряжая, запуская и активизируя базовые механизмы речевой деятельности.

Каков же сегодня психоневрологический портрет ребенка, посещающего логопункт или логопедическую группу:

- отличие от нормы по показателям физического и нервно-психического развития;

- эмоциональная возбудимость и неустойчивость;

- неустойчивость и истощаемость нервных процессов;

- отсутствие длительных волевых усилий и саморегуляции;

- отставание в развитии двигательной сферы, двигательная неловкость и беспокойство, малые объемы движений, недостаточная двигательная переключаемость, расстройство координации;

- быстрая и легкая возбудимость (легко отвлекаются и нетерпеливы);

- частая заторможенность (скованные и инертные);

- недостаточная сформированность мелкой моторики, и координации движений (особенно у детей с дизартрическим компонентом);

- миофункциональные нарушения (деформации зубо-челюстного строения, нарушения прикуса, твердого и мягкого неба, небно-глоточного затвора);

- дизартрический компонент (особенно на фоне проявлений органического поражения ЦНС в виде стертых парезов, мышечной гипотонии, спастичности, гиперкинезов, синкенезии);

- нарушения пространственно-временных представлений;

- сенсорная дезинтеграция; 
- глазодвигательные нарушения, сужение полей зрения, нистагмы, астигматизмы.

В большинстве своем здесь отражены признаки несформированности первого функционального блока мозга по А. Р. Лурия, так называемого энергетического. В данный блок входят все подкорковые структуры головного мозга: ствол, со всеми сложнейшими образованиями, включая ретикулярную формацию и стриопаллидарную систему, лимбическую систему и медиобазальные отделы коры лобных и височных долей. Формируется этот блок до 3 лет. Выполняет наиважнейшую проводящую и регулирующую функцию, отвечая за энергетический тонус и энергетическое состояние всего головного мозга. По Т. Г. Визель это так называемый стволово-подкорковый базис речи, который и определяет фундаментально базовую основу речепорождения. Если данный блок как фундамент оказывается пораженным, то это ставит под угрозу все «строение», на дефектной основе формируются все мозговые структуры и вся высшая психическая деятельность.

Исходя из вышесказанного становится понятно, что в современном образовательном мире хороших результатов в логопедической работе без применения нейропсихологического подхода добиться невозможно. В образовательном учреждении «Детский сад № 233 ОАО "РЖД"» данный подход охватывает все сферы педагогической деятельности: коррекционно-образовательную, научнометодическую, взаимодействие с педагогами, взаимодействие с родителями. Вся коррекционно-образовательная деятельность пронизана нейропсихологическим подходом. Занятия у логопеда и психолога проходят с применением нейростимуляции, межполушарного взаимодействия, мозжечковой стимуляции и учетом сенсорной интеграцией.

Понимание важности этого метода и подхода необходимо не только логопеду, дефектологу, психологу и воспитателю. Поэтому в целях распространения этого подхода огромная работа ведется со всем педагогическим коллективом, воспитателями и педагогами. В нашем образовательном учреждении воспитатели давно уяснили значимость данной инновации и активно прибегают к данному подходу как на занятиях, так и в режимных моментах группы. Регулярно с методической периодичностью проводятся мастер-классы, практикумы, коучингтренинги для педагогов.

Тесная взаимосвязь организуется с родителями детей, посещающих логопункт. Индивидуальные и групповые консультации с родителями, открытые занятия с детьми для родителей, обучающие тематические ролики на сайте сада. У каждого специалиста создано онлайн-сообщество в рамках образовательного учреждения, где каждый из нас делится практическим опытом, играми и приемами не только по артикуляционной гимнастике, но и дыхательной, мимической, голосовой гимнастике с применением биоэнергопластики, кинезиотерапии, психогимнастики, самомассажа.

Отметим, что каждый участник данного взаимодействия становится не только субъектом, но и объектом лечебного и восстановительного процесса. Так как, играя с ребенком в различные нейроигры, используя нейростимуляцию, мы помогаем сами себе тоже, активизируя работу своего мозга. 
И. В. Савиткина. Нейропсихологический подход в диагностике и коррекции нарушений речи у дошкольников

Коррекционные педагогические технологии, используемые с учетом нейропсихологического подхода, активизируют все необходимые компоненты психоречевого развития ребенка: речевой компонент - биоэнергопластика, фонетическая ритмика, логоритмика, психогимнастика; познавательный компонент - песотерапия, сказкотерапия, артерапия, ИКТ (БОС-технологии); двигательный компонент - кинезиотерапия, релаксация, самомассаж, глазодвигательная гимнастика, мозжечковая стимуляция.

В каждой группе, в кабинетах логопеда и психолога создается богатая и насыщенная предметно-развивающая среда для детей, в которой используются твистеры, балансировочные доски, массажные коврики, кинезиологические доски, кинезиологические дорожки, дары Фребеля и другой разнообразный материал, позволяющий реализовать именно нейропсихологический подход в коррекции и развитии речи детей.

Результатом кропотливой совместной работы является то, что в ходе посещения дошкольного учреждения дети, имеющие то или иное нарушение в развитии, получают необходимый «толчок» для включения своих компенсаторных возможностей. Таким образом, активизируются его природные ресурсы, которые помогают ребенку достичь своего оптимального преддошкольного уровня.

Литература

1. Архипова Е. Ф. Стертая дизартрия у детей. Москва: АСТ: Астрель. Хранитель, 2006. 319 с. Текст: непосредственный.

2. Ахутина Т. В. Порождение речи. Нейролингвистический анализ синтаксиса. Москва: Просвещение, 2002. 72 с. Текст: непосредственный.

3. Вендина Т. И. Введение в языкознание. Москва: Высшая школа, 2001. С. 112-186. Текст: непосредственный.

4. Визель Т. Г. Значение процессов полушарного взаимодействия в патогенезе нарушения речи // Ассиметрия. 2010. № 4. С. 9. Текст: непосредственный.

5. Винарская Е. Н. Дизартрия. Москва: АСТ: Астрель. Хранитель, 2006. 141 с. Текст: непосредственный.

6. Волкова Г. А. Логопедическая ритмика. Москва: Владос, 2002. 272 с. Текст: непосредственный.

7. Выготский Л. С. Мышление и речь: сборник. Москва: АСТ: Хранитель, 2008. 668 с. Текст: непосредственный.

8. Гвоздев А. Н. Избранные труды. Москва: Просвещение, 2000. 460 с. Текст: непосредственный.

9. Лопатина Л. В. Изучение и коррекция нарушений психомоторики у детей с минимальными дизартрическими расстройствами // Дефектология. 2003. № 4. С. 12. Текст: непосредственный.

10. Лурия А. Р. Основы нейропсихологии: учебное пособие для студентов высших учебных заведений. Москва: Академия, 2003. 384 с. Текст: непосредственный.

11. Мастюкова Е. М. Ребенок с отклонениями в развитии: ранняя диагностика и коррекция. Москва: Просвещение, 1992. 95 с. Текст: непосредственный.

12. Основы теории и практики логопедии / редактор Р. Е. Левина. Москва: Альянс. 2013. 368 с. Текст: непосредственный.

13. Семенович А. В. Нейропсихологическая коррекция в детском возрасте. Метод замещающего онтогенеза: учебное пособие. Москва: Генезис, 2007. 474 с. Текст: непосредственный. 
14. Хватцев М. Е. Логопедия. Москва: ВЛАДОС, 2010. Кн. 1. 272 с. Текст: непосредственный.

Статья поступила в редакиию 05.06.2021; одобрена после рецензирования 05.07.2021; принята к публикации 29.11.2021.

\section{NEUROPSYCHOLOGICAL APPROACH IN THE DIAGNOSIS AND CORRECTION OF SPEECH DISORDERS IN PRESCHOOLERS}

Irina $V$. Savitkina

Senior Lecturer,

Dorzhi Banzarov Buryat State University

24a Smolina St., Ulan-Ude 670000, Russia

savitirina@mail.ru

Abstract. The article is devoted to the application of neuropsychological approach to modern speech therapy and education of children in general. The presented material gives evidence of the importance and exclusivity of using this method in diagnosis and treatment of various speech disorders, as well as deviations in psychophysical development. We have build a summarized psychoneurological profile of the child, and considered the problems of socialization of modern children, their mental development and inclusion of all subjects of the learning process in the work for providing timely, high-quality assistance. In this regard, we have described the experience of interaction of all the subjects of the learning process in a particular preschool institution within the framework of the special education program, as well as the subject-developing environment and methodological materials used for the work. Keywords: neuropsychology, neurologopedics, speech production, intervention effect, neurostimulation, sensory integration of language phenomena generalization, speech perception, perception of speech activity, psychoneurological profile.

\section{For citation}

Savitkina I. V. Neuropsychological Approach in the Diagnosis and Correction of Speech Disorders in Preschoolers. Education. Person. Society. 2021; 2: 65-70 (In Russ.).

The article was submitted 05.06.2021; approved after reviewing 05.07.2021; accepted for publication 29.11.2021. 